\title{
Reshaping Indonesian Students Training for IOI
}

\author{
M. M. Inggriani LIEM \\ Knowledge and Software Engineering Research Group \\ School of Electrical Engineering and Informatics, Institut Teknologi Bandung, \\ Jalan Ganesha 10, Bandung, Indonesia \\ e-mail: inge@informatika.org
}

\begin{abstract}
Indonesia has been participating at IOI (International Olympiad in Informatics) since 1995. This paper presents a result of qualitative study of Indonesian IOI participants. The supporting data are obtained from a questionnaire distributed to the IOI 2006 - IOI 2015 participants, interviews, training database, journals, and reports from the national training program. Main objective of the study is to investigate the suitability of our training program to IOI expectations. From 35 distributed questionnaires, we obtained 24 respondents. Without having prior knowledge in Computer Science, solid mathematical foundation, and algorithmic problem solving in formal education, the national training curriculum can only give the participants a foundation for general problem solving which is not enough for IOI due to increase of creativity, complexity and difficulty of IOI tasks. That is why Indonesia achievement is stabilized in bronze. Almost all of Indonesian IOI alumni are working or studying in the domain of informatics and still participating programming competitions after IOI. Most of all Indonesian IOI participants are studying in top universities and some of them are working in the worldwide prestigious IT companies.
\end{abstract}

Keywords: Indonesian IOI training program, qualitative research, IOI tasks.

\section{Background}

Amongst its objectives, IOI has two main objectives for the contestants: to give recognition to young people who are exceptionally talented in the fields of informatics, and to foster international relationships among them.

The first participation of Indonesia at IOI was in 1995, by the initiative of young lecturers of UI (Universitas Indonesia) who were studying in US. The training and selection of Indonesian participants was informal and voluntary, it then found its shape as an organization in 2004, two years after the first Indonesian National Science Olympiad (OSN). The support and sponsorship from the Indonesian Ministry of Education for IOI and other International Olympiad is important. But the policy of the government that aims to catch the potential candidates from all provinces of Indonesia becomes a problem. Indonesia has more than 4 million high school students spread into more than 17,000 islands, from remote area to big cities. The quality of education in remote area is 
less in big cities like Java due to infrastructure gap. Students in big cities are more advantageous in education. Also, getting medals in OSN is considered prestigious and give good impact to the winners as well as to the school. Therefore, some schools in big cities (Jakarta, the capital, and some others province capitals) recognize the importance of the National Science Olympiad for their reputation, so that they are trying to get teachers or trainers. Most students who are interested in computer games became interested in programming, and by the support of their parents, they got private trainers for programming. This situation causes a broader gap.

The national selection process should keep a balance between "potential candidates" from remote areas and "ready to compete" candidates from the big cities. Up until now, Indonesia cannot be classified as a top performing country in the IOI. Nonetheless, its performance is improving and become more stable in bronze medals (Yugo et al., 2014). The summary of Indonesian team achievement in IOI from 2006 to 2015 is figured in Table 1.

This study was conducted with aim to reshape Indonesian national training program so that improvement can be achieved by being stable in silver medals. We gathered information from the past Indonesian IOI participants by giving a questionnaire. We investigate what Indonesian IOI participants are doing after their experience in IOI. It is important for the IOI community to know about their alumni after 9-10 years.

\section{Related Works}

Our work was inspired by the usage of qualitative research in computer science education. Formerly, the qualitative research has been applied to social research. Applying it to science and technology is quite rare. Recently, this method became widely used for informatics in education. M. Knobelsdorf (2008) presented a research using qualitative method in teaching of programming. A. Theodoraki and S. Xinogalos (2014) presented a qualitative study on student's attitudes towards learning programming through

Table 1

Indonesian Participant Medal Achievement at IOI 2006 - IOI 2015

\begin{tabular}{llll}
\hline Year & Gold & Silver & Bronze \\
\hline 2006 & 0 & 1 & 0 \\
2007 & 0 & 0 & 4 \\
2008 & 1 & 0 & 3 \\
2009 & 0 & 2 & 1 \\
2010 & 0 & 2 & 1 \\
2011 & 0 & 0 & 2 \\
2012 & 0 & 1 & 2 \\
2013 & 0 & 2 & 2 \\
2014 & 0 & 0 & 4 \\
2015 & 0 & 2 & 1 \\
\hline
\end{tabular}


games. Hazzan et al. (2006) wrote about qualitative research in computer education. He also wrote about teaching and learning qualitative research by conducting qualitative research (Hazzan, 2014). In our case, this method is applied to the training and selection program of Indonesian Olympiad participants.

A survey done and reported by Nedkov et al. (2012) concerning the selection, preparation and participation of IOI teams of Bulgaria, Croatia, Latvia, Poland, and Slovakia. Those countries are the leading countries in the IOI. According to this survey, factors contributed to the successful participation are traditions, strong emphasis on mathematics in national education, targeted extra-curricular activities, early start and gaining experience by participating in competitions, systematics management and dedicated people, motivation and rewards.

\section{Objectives}

This study is conducted in order to obtain findings related to:

a. Factors that help the participants to get medal in IOI.

b. Fitness of Indonesian training topics to IOI tasks.

c. The influence of IOI to the career of IOI participants.

The first questions are the most important since one of the main targets of IOI participation is to win the competition that is getting medals, and the Indonesian education system has had bad results in mathematics in the PISA 2012 test. The Program for International Student Assessment (PISA) is a worldwide study by the Organization for Economic Cooperation and Development (OECD) in member and non-member nations of 15-year-old school pupil's scholastic performance on mathematics, science, and reading ${ }^{1}$. For winning a competition, a supporting curriculum is needed. The third question is trying to track the career of the Indonesian IOI participant, since life is going on after IOI.

\section{Design Experiment}

This paper analyse the data obtained from Indonesian IOI participants from 2006 to 2015. During these last ten years, Indonesia has sent 40 participants (IOI alumni), 5 of them have been participated twice. Therefore, we had 35 persons in the IOI during that period. From the 35 Indonesian IOI alumni, we obtained 24 responses in two weeks by contacting 3 alumni and asked them to contact the others. It makes over $70 \%$. This is a proof that there is a close relation between the coaches and the alumni, as well as between alumni. Three years after IOI, they are still active in programming competition, as contestants in international competitions, Scientific Committee or Technical Committee on Indonesian National Training program and competition.

\footnotetext{
${ }^{1}$ http://www. oecd.org/pisa/keyfindings/pisa-2012-results.htm
} 
The data are obtained from the following sources:

a. Indonesian National Training Program database, which are the participants, and also the training program archives (journal, schedule, report).

b. Questionnaires, via Google questionnaires as well as via email.

c. Literature reviews for getting information about IOI tasks and solutions.

\section{Findings and Discussions}

Based on the questionnaire, we identify some findings, which are described in the following sections.

\subsection{Effectiveness of the National Training Program}

In the beginning, Indonesia did not have a systematics training program. Talented high school students surround university faculty members were trained only a few weeks before the IOI. Since 2002, the Ministry of Education of Indonesia has initiated the National Science Olympiad (OSN), where programming is one of the competition subjects amongst 6 others (mathematics, physics, chemistry, economy, geology and astronomy). In OSN, 80 to 100 high school students that have passed the successive selection at the level of school, region, and then provinces are invited to come for a national competition held in one of the city in Indonesia. Each year, the scientific committee must run two concurrent programs: one for national selection (from school to OSN), while the other is a program for trainings and selections for the next IOI.

One cycle of trainings and selections of IOI participants takes one year consists of four phases (I, II, III, IV) training camps. Between two successive camps, candidates must join on-line mentoring and challenge, and also participate in other informatics contests. Thirty candidates of OSN winners enter the phase I. After three weeks of training, the scientific committee selects 16 top scorers to enter phase II. At the end of phase II, eight participants are selected for phase III. Finally, only four participants undergo phase IV becoming the official Indonesian IOI participants.

The organization of the training is getting better by having more IOI alumni and their involvement. Most of the alumni are graduated in informatics and then they work in worldwide prestigious information technology and software companies. Their experience both in competition, education as well as in their professional works helps to improve the training and selection programs. Some of the IOI alumni participate voluntarily in the scientific committee as well as the technical committee for the two concurrent programs. They become mentors and problem setters in both programs. They also set up an alumni organization (IA-TOKI) and have a close relationship with the scientific committee, though they are scattered all over the world. They are developing a contest management system which is used for on-line training program and some other regional/ local programming competitions nowadays. The contribution of IA-TOKI to the national training program is significant. 
Almost all of the respondents answer that the on-site training camps are very important and more effective than the on-line training:

1. They learn more from the mentors and from the peers during on-site training. Direct discussions are more effective than on-line learning.

2. They can focus more during the on-site training, compared to on-line training. The students in an on-site training are relieved from school so that they can fully concentrate on the IOI preparation. On the other hand, students must prioritize their school and daily tasks during on-line training.

3. They have a competitive environment during on-site training, especially in simulation sessions. Simulation trains the students how to manage their stresses, and builds a competitive sense by the presence of other students.

4. Being together with peers during on-site training for weeks made the students know each other better where they built a team spirit, and becomes friends.

5. They have a better internet connection.

There is one exception. One respondent stated that he prefer on-line training and self-studying, and learning from worldwide existing on-line competitions, books and on-line programming competition websites. It is then identified that his level is higher compared to his peers, so that he became bored during the on-site training, though he attended and completed the whole on-site training programs. He was the one that achieved a gold medal in IOI 2008.

\subsection{Other Contributing Factors}

Other factors that contribute the medal achievement are self-exercise, reading books, on-line resources, and other competitions that made them regularly connect to the world of competition.

When they are not in a training camp, $54 \%$ of the respondents were exercising themselves more than 10 hours per week, $17 \%$ only between 5 to 10 hours per week, $17 \%$ at least 3 hours per week, and $13 \%$ exercise irregularly.

They also try to solve past IOI tasks, but not so much. $46 \%$ solve more than 10 tasks, $17 \%$ between 5 to 10 tasks, $25 \%$ less than 5 tasks, and $8 \%$ does not try to solve in past IOI tasks, and $4 \%$ did not comment. Trying past IOI tasks seems not so interesting because they know that IOI tasks are very creative.

The following two figures (Fig. 1 and Fig. 2) illustrate those findings.

Other learning resources (Fig. 3) are websites and competition sites. $75 \%$ of the respondents state that learning from the websites such as Topcoder, Usaco and SPOJ are useful. $71 \%$ of them state that participation in competition is useful as preparation for IOI.

Learning from textbooks seems to be least favourite option for this young generation. Only $33 \%$ of the respondents were learning from textbooks. Only two textbooks are mentioned explicitly: Introduction to Algorithms (by Thomas H. Cormen, Charles E. And Leiserson), and Competitive Programming (by Steven Halim). 


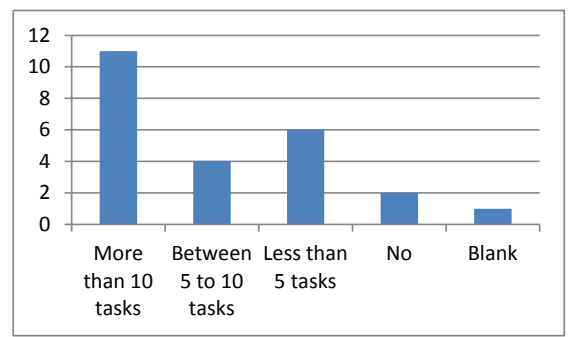

Fig. 1. Hours Spent by Indonesian IOI Participant for self-preparation.

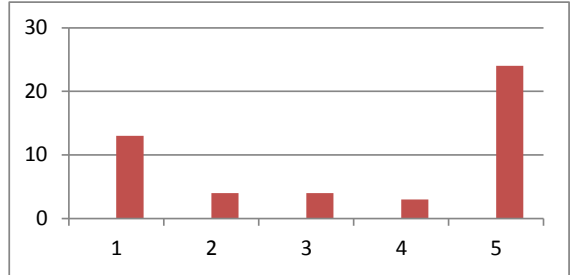

Fig. 2. Number of IOI Tasks exercised by Indonesian IOI Participant.

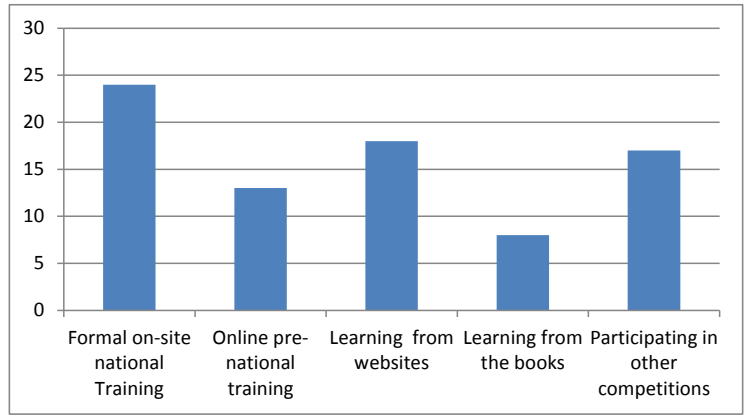

Fig. 3. Various Ways of Learning for IOI preparation.

Besides the national training program, all of the respondents participate regularly in the worldwide competitions, not only in the period of national training, but also few years after participating IOI. Competition becomes their hobbies, and they are getting more and more experience in that domain so that they become the national scientific members and trainers in a national training program or task contributors in prestigious international programming competitions. Their favourite competition websites are TopCoder, Codeforces, Usaco, APIO, COCI, CEOI, Joint, BEOI, Google Code Jam, ACM ICPC, and local competitions.

One of the alumni mentioned that the following ingredients are important for being successful in IOI: grit/ perseverance, time management and prioritization, attention to detail, creative thinking, the ability to recognize pattern on problems, experience with common tricks and avoiding common pitfalls, experience with a breadth of topics. 


\subsection{Fitness of Training Topics to IOI Tasks}

A curriculum of the training program is progressing continuously since 2006, in three periods. During the first period (2006-2010), most of the trainers are the university faculty members. IOI alumni participation in the second period (2011-2013) and the third period (2014-2015) brings new colour to the program. The ambiance of programming competition becomes stronger. More than that, the creative problem solving exercises is introduced in addition to the classical training subject. The scientific committee is working together with IOI alumni closely for the training program subjects and tasks.

In the beginning, the phase I of training is dedicated to assure the basic foundation of CS (programming, advanced topics, while phase III is dedicated to simulation and the selection of four IOI participants. Phase IV is the final preparation before going to the IOI.

From one year to another, IOI tasks become more creative, unpredictable and difficult (Halim, 2013). All countries' training program must anticipate these changes and shifted accordingly. As a consequence, Indonesia decides to shift the basic skill gradually from on-site to on-line training by providing on-line course material in Indonesian contest management systems. The students should develop their self-learning capability. This solution works well for students living in big cities with good infrastructure as well as good internet reliability and availability, and good teachers are available. In addition to the shifting of basic skills in CS, exercise and simulations are designed to be harder and more challenging. Table 2 illustrates the different strategies of the three periods.

As illustrated above in Table 1, the achievement of Indonesian team is stabilized in Bronze medals. The year 2008 is a special year with one gold medal obtained by a prodigious student. The year 2011 is also exceptional with only one bronze obtained because of two reasons: a transition of the training method and too much given exercises that are not in the IOI style.

Table 2

Overview of Training Program Curriculum from 2006 to 2015

\begin{tabular}{lllll}
\hline IOI year & Training Phase I & Training Phase II & Training Phase III & Training Phase IV \\
\hline 2006-2010 & $\begin{array}{l}\text { Basic programming } \\
\text { Basic Exercises } \\
\text { Simple simulation }\end{array}$ & $\begin{array}{l}\text { CS topics, strategic prob- } \\
\text { lem solving } \\
\text { Simulation }\end{array}$ & $\begin{array}{l}\text { Advance Topics and } \\
\text { Simulation }\end{array}$ & Final IOI preparation \\
2011-2013 & $\begin{array}{l}\text { Basic programming } \\
\text { CS Topics, strategic } \\
\text { problem solving, } \\
\text { simulation }\end{array}$ & $\begin{array}{l}\text { Advanced Topics and ad- } \\
\text { vanced problem }\end{array}$ & $\begin{array}{l}\text { Advanced Topics and } \\
\text { simulation }\end{array}$ & Final IOI preparation \\
2014-2015 & $\begin{array}{l}\text { CS Topics and } \\
\text { Advanced Topics \& } \\
\text { strategic problem } \\
\text { solving, simulation }\end{array}$ & $\begin{array}{l}\text { Special advanced topics } \\
\text { More Simulation }\end{array}$ & $\begin{array}{l}\text { More Simulation, } \\
\text { more ad-hocs problem }\end{array}$ & Final IOI preparation \\
\hline
\end{tabular}


This part is a deeper look to the subjects covered during the training programs, contains the analysis among the topics covered in the Indonesian training and IOI tasks.

As mentioned above, the Indonesian high school curriculum does not cover computer science as a compulsory subject, compared to other countries where the computer science concepts has been introduced since the earlier age, from 10-14 years (Dagienè and Futschek, 2010, Nedkov, 2012). Three phases of training, each lasts for 3 weeks can cover all the required topics suggested by IOI curriculum. However, topics such as strategic problem solving and thinking take time to be mastered. Many exercises are also needed in order to construct the pattern of problems as well as the pattern of solutions. These patterns are important for solving the creative IOI task.

The national training program topics covered the last version of the IOI syllabus, obtained from the website ${ }^{2}$. National Training topics exclude basic computer science and mathematics listed in the IOI syllabus and respondents made remarks regarding the importance of those topics (Fig. 4) for IOI.

In a questionnaire after IOI 2015, a list of topics is given. The country leaders were asked to rate the importance of them. In this study, we also try to explore the opinions of respondents regarding these topics, and we got the following results: Maximum flow, flow/cut duality theorem (67\%); Strongly connected components, bridges and articulation points (54\%); Heavy-light decomposition and separator structures for static trees (25\%); Data structures for dynamically changing trees and their use in graph algorithms (54\%); Topics in number theory (33\%); String algorithms (54\%).

Additionally, IOI tasks and solutions from IOI 2006 to IOI 2015 were analysed. The respondents are asked to mention the most interesting, the most difficult, and the most memorable IOI tasks. From these, we obtained 74 tasks. These tasks are then cross checked to the topics listed.

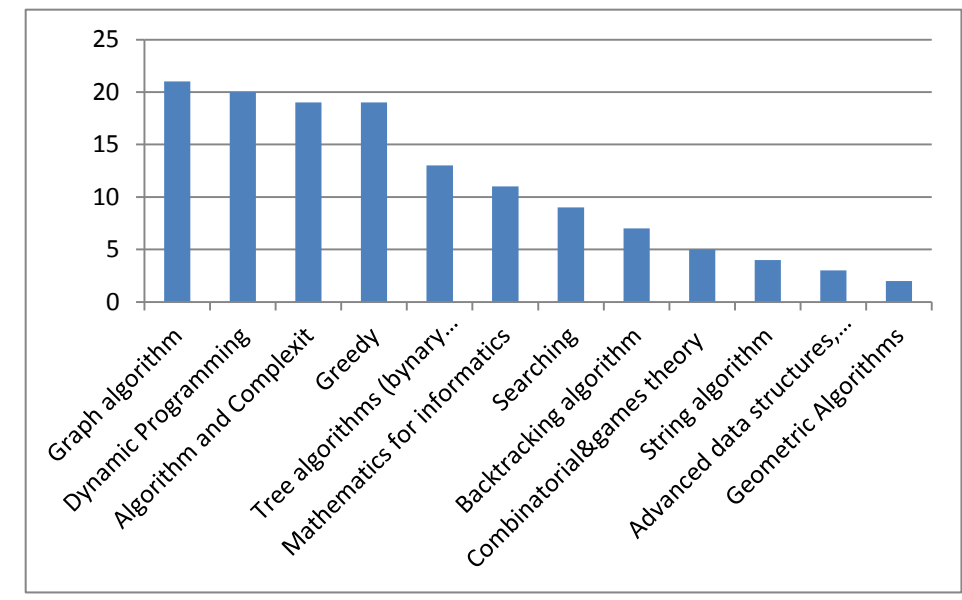

Fig. 4. Importance of Training Topics.

2 http://ksp.sk/ misof/ioi-syllabus/ 
The summary of this cross check and analysis illustrate the applicability of our training topics for solving IOI tasks:

- The importance of the topics ranked in figure Fig. 4 has high correlations with the technics needs to solve the IOI tasks.

- Graph, DP, Greedy, sort and search are very important, but they alone are not enough, since the variation and specific condition of the graph can improve the algorithm.

- Algorithm complexity is important for measuring the performance of algorithm in order to solve more difficult subtasks.

\subsection{Influence of IOI to Participants Careers}

IOI influences strongly to the Indonesian participants careers. By winning medals in IOI, they can enter easily to top Indonesian universities in Informatics, even entering the top universities in the world. All of the participants are studying in the fields of informatics as shown by the following graphics in Fig. 5.

Most of the Indonesian alumni of IOI 2006-2008 have graduated from bachelor degree and now working or studying PhD level. Some of them are founders or CTO at top start-up Indonesian companies in the domain of software, offers internship and employees their juniors. Some medallists are working for prestigious companies in the US and UK as software developers. The younger alumni are now studying in bachelor or master program in informatics. Only 2 of 24 participants are studying in other domains: one is studying in medical faculty, and another is studying in the first common year (he is intended studying in informatics). This finding shows that IOI is a starting point for their study and then their career in informatics. The IOI gave them motivation for studying and working abroad. IOI medal is a free ticket to enter top universities and obtaining scholarships.

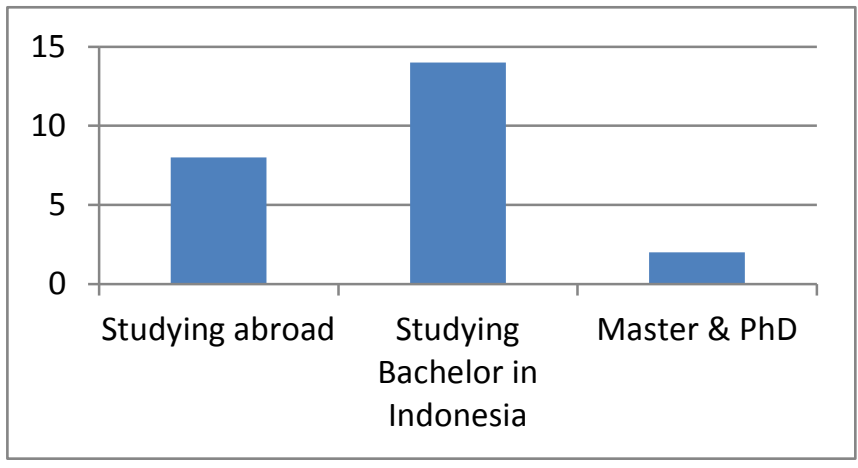

Fig. 5. Indonesian IOI Alumni Tracking. 


\section{Conclusions}

This paper presents a study of Indonesian IOI participants from 2006 to 2015, where the data come from questionnaire distributed to them, interviews, national training database, journal of national training program, and from training reports. The study aimed to identify the appropriateness of our national training program to IOI participation, since we have only 1 gold in 2008, and in the last 4 years our achievement is stabilized in bronze. With the limitation of respondents, the findings from the pass IOI in this study will be used to reshape our strategy in the coming year, for moving at least to silver. We must also consider that IOI task is getting more unpredictable, difficult, and creative (Halim, 2013).

Without having computer science, solid mathematical foundation, and algorithmic problem solving in their formal education, three phases of training each last for three weeks on-site plus three weeks extra for final preparation are not enough for preparing IOI gold medallist, unless we can find a prodigious student. Bebras challenge ${ }^{3}$ is a potential way to bridge the gap in computational thinking since an early age. Indonesia will join Bebras (Dagienė \& Stupurienè, 2014) during the coming year. Indonesia will remain participate actively in IOI since the outcome of the participation and achievement in IOI also improves the spirit of competition amongst Indonesian senior high school students which in turn also means improvement in quality of high school education in Indonesia.

Last but not least, this paper highlights the difference of Computer Science, mathematics education in elementary, middle and high school of IOI countries. Formal education in Computer Science, mathematics and problem solving from an earlier age contributes to the success of the participants in IOI. One year, or more precisely four training camps three weeks each, is not enough to well prepare IOI participants unless we are lucky to find an extraordinary student.

\section{Acknowledgment}

I would like to thanks Adi Mulyanto who help me connecting to the Indonesian IOI alumni for getting the data, and also to the 24 respondents for their quick responses to the questionnaires. I would also like to show my special gratitude to Prof. Valentina Dagiene, who introduced to me about qualitative research, inspired and encouraged me for writing this paper.

3 http://bebras.org/ 


\section{References}

Dagienė, V., Futcheck, G. (2010). Introducing informatics concepts through a contest. Presented in: IFIP Workshop New Developments in ICT and Education held at Université de Picardie Jules Verne, Amiens, France 28-30 June.

Dagienè, V., Stupurienė, G. (2014). Informatics education based on solving attractive tasks through a contest. Commentarii informaticae didacticae, 7, 97-115.

Halim, S. (2013). Expecting the Unexpected. Olympiad in Informatics, 7, 36-41.

Hazzan, O., Dubinsky, Y. et al. (2006). Qualitative research in computer science education. In: SIGCSE '06 Proceedings of the 37 $7^{\text {th }}$ SIGCSE Technical Symposium on Computer Science Education. 408-412.

Hazzan, O., Nutov, L. (2014). Teaching and Learning Qualitative Research $\sim$ Conducting Qualitative Research, The Qualitative Report 2014, vol 19, Teaching \& Learning Article 1, 1-29.

Knobelsdorf, M. (2008). A typology of CS preconditions for learning. In: Koli '08 Proceedings of the $8^{\text {th }}$ International Conference on Computing Education Research. 62-71.

Nedkov, P. (2012). Young Talent in informatics: preliminary findings of an IOI survey launched by AICA in cooperation with IT STAR. Olympiad in Informatics, 6, 192-198.

Theodoraki, A., Xinogalos, S. (2014). Studying students' attitudes on using examples of game source code for learning programming. Informatics in Education, 13(2), 265-277.

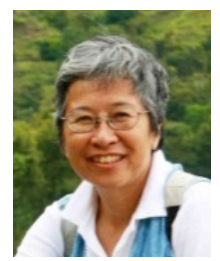

M. M. I. Liem is a member of Knowledge and Software Engineering Research Group, School of Electrical and Engineering, Institut Teknologi Bandung (ITB). She has been teaching programming in ITB since 1977 and obtained her doctoral degree in University of Joseph Fourier Grenoble France in 1989, with teaching programming as major topics of her dissertation. From 2004, she is involved as a team member in national recruitment, training and IOI preparation for Indonesian team. 